\title{
Tool for Assessment of Rural Oral Health Determinants
}

\author{
Saira Siraj E. ${ }^{1}$, Pallavi H. Nagaiah², Pushpanjali Krishnappa ${ }^{3}$ \\ ${ }^{1}$ Department of Public Health Dentistry, Azeezia College of Dental Sciences and Research, Kollam, \\ Kerala, India. ${ }^{2}$ Department of Public Health Dentistry, Bangalore, Karnataka, India. ${ }^{3}$ Department of \\ Public Health Dentistry, Faculty of Dental Sciences, MSRUAS, Bangalore, Karnataka, India.
}

\section{ABSTRACT}

\section{BACKGROUND}

Rural populations facing several challenges such as lack of man power, poor accessibility, poverty, illiteracy and many others. Assessment of determinants of oral health becomes essential in developing policies to improve health among such disadvantaged population. The objectives of this study were to develop a Rural Oral Health Determinants (ROHD) tool and identify the determinants of dental caries, gingivitis and periodontitis.

\section{METHODS}

Rural Oral Health Determinants tool was developed based on literature review and expert opinion and its content validity was evaluated. A cross sectional study was carried out among the residents of 206 households in T Hosur village, Karnataka to assess the test-retest reliability and to identify the determinants of dental caries, gingivitis and periodontitis. Data on determinants of oral health were collected using validated ROHD tool and the oral health status was recorded using world health organization (WHO) proforma 2013. Descriptive and Chi square analysis were performed.

\section{RESULTS}

Test retest reliability of ROHD tool as measured by intra-class correlation coefficient ranged from 0.72 - 1 . Amongst the various determinants of oral health age, marital status, type of sugar consumption, number of dental visits in the last one year were found to be significantly associated with dental caries. Individuals aged $\geq 36$ years and married subjects were more likely to have gingivitis. Periodontitis was strongly associated with age, marital status, education and paternal education.

\section{CONCLUSIONS}

ROHD tool has acceptable validity and reliability and can be used as an effective tool to identify comprehensively the determinants of oral health among adults in rural communities.

\section{KEY WORDS}

Dental Caries, Gingivitis, Oral Health, Periodontitis, Rural Population

\author{
Corresponding Author: \\ Dr. Saira Siraj E., \\ Senior Lecturer, \\ Department of Public Health Dentistry, \\ Azeezia College of Dental Sciences and \\ Research, Meeyannoor P.O, \\ Kollam - 691537, Kerala, India. \\ E-mail: sairasirajsk@gmail.com
}

DOI: $10.14260 /$ jemds $/ 2021 / 473$

How to Cite This Article:

Siraj ES., Nagaiah PH, Krishnappa P. Tool for assessment of rural oral health determinants. J Evolution Med Dent Sci 2021;10(30):2314-2319, $10.14260 /$ jemds/2021/473 DOI:

Submission 05-05-2021,

Peer Review 03-07-2021,

Acceptance 12-07-2021,

Published 26-07-2021.

Copyright (C) 2021 Saira Siraj E. et al. This is an open access article distributed under Creative Commons Attribution License [Attribution 4.0 International (CC BY 4.0)] 


\section{BACKGROUND}

Determinants of health are the range of personal, social, economic and environmental factors which determine the health status of individuals and populations. ${ }^{1}$ These factors interact and these interactions may be health promoting or deleterious. Conceptually the health of individuals and whole communities may be considered to be the result of many interactions. $^{2}$ This relationship also applies to oral health, which is an integral and inseparable contributor to general health. There are widespread inequalities in oral health outcomes within and between different countries of the world. ${ }^{3}$ Addressing these determinants will bring sustainable improvement in the health of population and reduction in health inequalities. Oral diseases remained still a public health problem for developed countries and a burden for developing countries like India especially among the rural population. ${ }^{4}$ According to 2011 census, out of the total of 1210.2 million population in India, the size of rural population is 833.1 million (or $68.84 \%$ of the total population). ${ }^{5}$ Rural populations are being faced by several challenges such as lack of man power, poor accessibility, poverty and illiteracy. Studies have shown lack of health education, preventive services and adequate oral hygiene practices among the low income communities and rural areas. ${ }^{6}$

In a study on rural population of Nellore district, prevalence of dental caries was reported to be $39.3 \%, 53 \%$, $77.3 \%$, and $81.8 \%$ in 5, 12, $35-44$ and $65-74$ year old, respectively. ${ }^{7}$ According to Agarwal et al. 2010, periodontal disease is more prevalent in the rural population of India. ${ }^{8}$ Kalyanpur R et al. in 2011 and Shah N et al. in 2004 compared the prevalence of tooth loss among rural and urban subjects and their findings concluded greater prevalence of tooth mortality in rural compared to urban Indian population. ${ }^{9} \mathrm{~A}$ study done by Batra et al. 2014 reported a significant association between age, smoking, tobacco chewing with periodontal disease among rural population. ${ }^{10}$ According to Miglani S 2020, prevalence of caries is not uniform throughout the subgroups of a country and is more prevalent in poor and low socioeconomic groups. ${ }^{11}$ Gupta $\mathrm{R}$ et al. in 2013 identified age, mouth rinsing frequency, teeth cleaning material, teeth cleaning frequency, mother's education and dentist visit as the associated factors with dental caries in rural areas. ${ }^{12}$ Disparities in exposure and vulnerability to diseases and health services accessibility are pronounced in India with the most affected people being the poorest and most disadvantaged. ${ }^{13}$ Recently, increasing emphasis has been placed on the importance of economic, social and environmental factors in the understanding of oral diseases, and public health research has focused on the determinants of health and disease. ${ }^{14}$ Thus, analyzing the relationship between these determinants and oral health is of great importance and such analysis enables in planning oral health care services for the population. Moreover, there is a great paucity of data pertaining to determinants of oral health in this disadvantaged population. Currently there are no validated tools available to measure comprehensively the determinants of oral health in rural and remote communities. Hence, developing a tool to identify the determinants of oral health becomes essential in developing policies to improve health among such disadvantaged population.

\section{Objectives}

The objectives of this study were to develop Rural Oral Health Determinants tool and identify the determinants of dental caries, gingivitis and periodontitis.

\section{METHODS}

A cross sectional study was conducted among the population of $\mathrm{T}$ Hosur village, Kaiwara (hobli) in Chikkaballapura district, Karnataka from April 2016 to September 2016. The study proposal was drafted and ethical clearance was obtained from Institutional Ethical Committee. Informed consent was obtained from the subjects to be a part of the study. Parental consent and assent were also obtained from the children who participated in the study. The study was conducted in two phases: -

\section{Phase I}

Developing Rural Oral Health Determinants (ROHD) tool and assessing the content validity.

A tool was developed to identify the determinants of oral health namely social, cultural, biological, psychological and environmental based on literature review and expert opinion provided by faculty members of Department of Community Medicine and Public Health Dentistry. The tool was sent to a panel of seven members including experts of public health who had knowledge about the determinants of health and oral health among rural population. The content validity was assessed using Lawshe method. ${ }^{15}$ The original version had 36 items. Lawshe, states that when a content evaluation panel is composed of seven members, a minimum content validity ratio (CVR) of 0.99 is required for each item to be retained in the final tool.

\section{Phase II}

Pilot study to assess the reliability of the Rural Oral Health Determinants (ROHD) tool and identify the determinants of oral health.

A pilot study was conducted among the residents of 206 households in T Hosur village to assess the reliability of the Rural Oral Health Determinants (ROHD) tool. All the required and relevant information about the number of households in $\mathrm{T}$ Hosur village were obtained from the primary health centre, Kaiwara. To conduct a pilot study $10 \%$ of houses from 206 households were determined i.e out of the 206 houses, 20 houses were selected. Systematic sampling method was used for the selection of samples. Sampling interval was calculated by dividing the total number of households by the sample size. Each of the houses in the $\mathrm{T}$ Hosur village was numbered. First house to be visited was selected randomly followed by systematic selection of every tenth house thereafter. All individuals $>15$ years of age in the selected houses were included in the study.

\section{Exclusion Criteria}

1) Subjects aged $\preceq 15$ years.

2) Subjects with debilitating health conditions. 
Two trained interviewers carried out all individual face to - face structured interviews with the help of two assistant (house surgeons) who knew the local language and thus ensuring face validity of ROHD tool. Oral health status was recorded using WHO proforma 201316. The oral examination of the study subjects were carried out in well illuminated rooms in their respective houses. If required, light emitting diode torchlight was used. The study subjects were then informed about their oral health status and appropriate referrals were given for curative dental services. The same subjects were interviewed one week later to assess the test retest reliability.

\section{Statistical Analysis}

Statistical program for social sciences (SPSS) version 16 was used for statistical analysis of data. Test retest reliability of ROHD tool was analysed using intra-class correlation coefficient. Descriptive statistics were derived in the form of proportions for the study sample with respect to each variable studied. The dependent variables such as dental caries, gingivitis and periodontitis were dichotomised for further analysis. Chi square / Fisher's exact test at $5 \%$ level of significance was used to test the association of the independent variables with the dependent variable. The variables which were significant after Chi square / Fisher's exact analysis were considered for odds ratio calculation and those variables with lesser distribution of subjects in the subgroup were excluded.

\section{RESULTS}

Content validity ratio of 1 was calculated for age, gender, education, income per month, sugar exposure, oral hygiene practices (except oral hygiene aids) and dental visit history. Items such as marital status, birth order positions, physical activity, general health status, psychological stress, nutritional assessment, employment status, maternal and paternal education, dietary habits were found to have least agreement (CVR $<0.99$ ) between the experts to be included in the tool. Following an intense literature search, researcher decided to retain certain items in the tool, despite of its low CVR. Hence the final validated ROHD tool contained 33 items. Test retest reliability of ROHD tool as measured by intra-class correlation coefficient ranged from 0.72 - 1 . Internal consistency was determined only for the dimension oral hygiene practices and cronbach's alpha was calculated to be 0.82. However, other variables such as social, cultural, biological and environmental factors were not amenable to this test as they were not dichotomized and measure multiple dimensions.

Table 1 shows the distribution of the study subjects based on the socio cultural and economic factors. Of the 71 study subjects, the age ranged from 16 to 89 , with the mean age being 38.08 years. There were 35 (49.3\%) males and 36 $(50.7 \%)$ females. In the present study 33 (46.5\%) were illiterate, 1 (1.4\%) had completed primary schooling, 6 (8.5 $\%)$ had completed middle school, 21 (29.6\%) had completed high school, 4 (5.6\%) had done diploma and 6 (8.5\%) had done graduation. Fifty six percent of the subjects were unemployed, 13 (18.3\%) were unskilled workers, 3(4.2\%) were skilled workers and 15 (21.1 \%) were semiprofessionals.

Table 2 shows the distribution of the study subjects based on the oral hygiene practices, adverse habits and dental visit history. Sixty five percent of the study subjects used tooth brush for cleaning and $35 \%$ reported of cleaning teeth with finger. Seventy eight percent of study subjects reported of brushing once daily and $51 \%$ rinse their mouth after every meal. Out of the total study population of 71, 17 (24\%) were found to be tobacco users and $54(76 \%)$ were non-tobacco users. Chewing tobacco is the most commonly consumed form $10(14.1 \%)$ as compared to the smoking form of tobacco 7 (9.9\%). Ninety percent of the study subjects did not visit the dentist in last one year, $7 \%$ had visited the dentist once in last one year and $3 \%$ had visited the dentist twice in last one year.

\begin{tabular}{|c|c|c|c|}
\hline \multicolumn{2}{|c|}{ Variables } & Frequency & Percentage \\
\hline \multirow{2}{*}{ Age (Years) } & 16 - 35 years & 34 & 47.9 \\
\hline & $\geq 36$ years & 37 & 52.1 \\
\hline \multirow{2}{*}{ Gender } & Male & 35 & 49.3 \\
\hline & Female & 36 & 50.7 \\
\hline \multirow{3}{*}{ Marital status } & Married & 47 & 66.2 \\
\hline & Unmarried & 19 & 26.8 \\
\hline & Widowed & 5 & 7.0 \\
\hline \multirow{6}{*}{ Education } & Illiterate & 33 & 46.5 \\
\hline & Primary & 1 & 1.4 \\
\hline & Middle school & 6 & 8.5 \\
\hline & High school & 21 & 29.6 \\
\hline & Diploma & 4 & 5.6 \\
\hline & Graduation & 6 & 8.5 \\
\hline \multirow{4}{*}{ Employment status } & Unemployed & 40 & 56.3 \\
\hline & Unskilled worker & 13 & 18.3 \\
\hline & Skilled worker & 3 & 4.2 \\
\hline & Semi-profession & 15 & 21.1 \\
\hline \multirow{3}{*}{ Maternal education } & Illiterate & 68 & 95.8 \\
\hline & Middle school & 2 & 2.8 \\
\hline & High school & 1 & 1.4 \\
\hline \multirow{6}{*}{ Paternal education } & Illiterate & 60 & 84.6 \\
\hline & Primary & 2 & 2.8 \\
\hline & Middle school & 4 & 5.6 \\
\hline & High school & 3 & 4.2 \\
\hline & Diploma & 1 & 1.4 \\
\hline & Graduation & 1 & 1.4 \\
\hline \multirow{3}{*}{ Income per month } & $<5000 \mathrm{Rs}$ & 31 & 43.7 \\
\hline & 5000 - 9999 Rs & 33 & 46.4 \\
\hline & $10,000-24,999 \mathrm{Rs}$ & 7 & 9.9 \\
\hline \multicolumn{4}{|c|}{$\begin{array}{l}\text { Table 1. Distribution of the Study Subjects Based on the } \\
\text { Socio Cultural and Economic Factors }\end{array}$} \\
\hline
\end{tabular}

\begin{tabular}{|c|c|c|c|}
\hline \multicolumn{2}{|c|}{ Variables } & Frequency & Percentage \\
\hline \multirow{2}{*}{ Type of cleaning } & Toothbrush & 46 & 64.8 \\
\hline & Finger & 25 & 35.2 \\
\hline \multirow{3}{*}{ Method of cleaning } & Vertical & 4 & 5.7 \\
\hline & Horizontal & 41 & 57.7 \\
\hline & Combination & 26 & 36.6 \\
\hline \multirow{2}{*}{ Frequency of cleaning } & Once & 55 & 77.5 \\
\hline & Twice & 16 & 22.5 \\
\hline \multirow{2}{*}{$\begin{array}{l}\text { Material used for } \\
\text { cleaning }\end{array}$} & Tooth paste & 49 & 69.0 \\
\hline & Charcoal & 22 & 31.0 \\
\hline \multirow{3}{*}{$\begin{array}{l}\text { Rinsing of mouth after } \\
\text { every meal }\end{array}$} & Yes & 36 & 50.7 \\
\hline & No & 35 & 49.3 \\
\hline & Users & 17 & 24.0 \\
\hline \multirow{3}{*}{ Type of tobacco use } & a. Smoking & 7 & 9.9 \\
\hline & b. Chewing & 10 & 14.1 \\
\hline & Non-tobacco users & 54 & 76.0 \\
\hline \multirow{3}{*}{$\begin{array}{l}\text { Number of dental visits } \\
\text { in last one year }\end{array}$} & Nil & 64 & 90.1 \\
\hline & Once & 5 & 7.0 \\
\hline & Twice & 2 & 2.9 \\
\hline \multicolumn{4}{|c|}{$\begin{array}{l}\text { Table 2. Distribution of the Study Subjects Based on the Oral Hygiene } \\
\text { Practices, Adverse Habits, and Dental Visit History }\end{array}$} \\
\hline
\end{tabular}

Mean DMFT (decayed, missing and filled permanent teeth) score among the study subjects was 1.17 . The prevalence of dental caries was found to be $50.7 \%$. Of the total of 71 study subjects, 52 were diagnosed as having gingivitis giving an overall prevalence of $73.2 \%$ whereas 41 
subjects were diagnosed with periodontal pockets (scores 1 , 2) and 35 subjects with loss of attachment (scores 1,2).

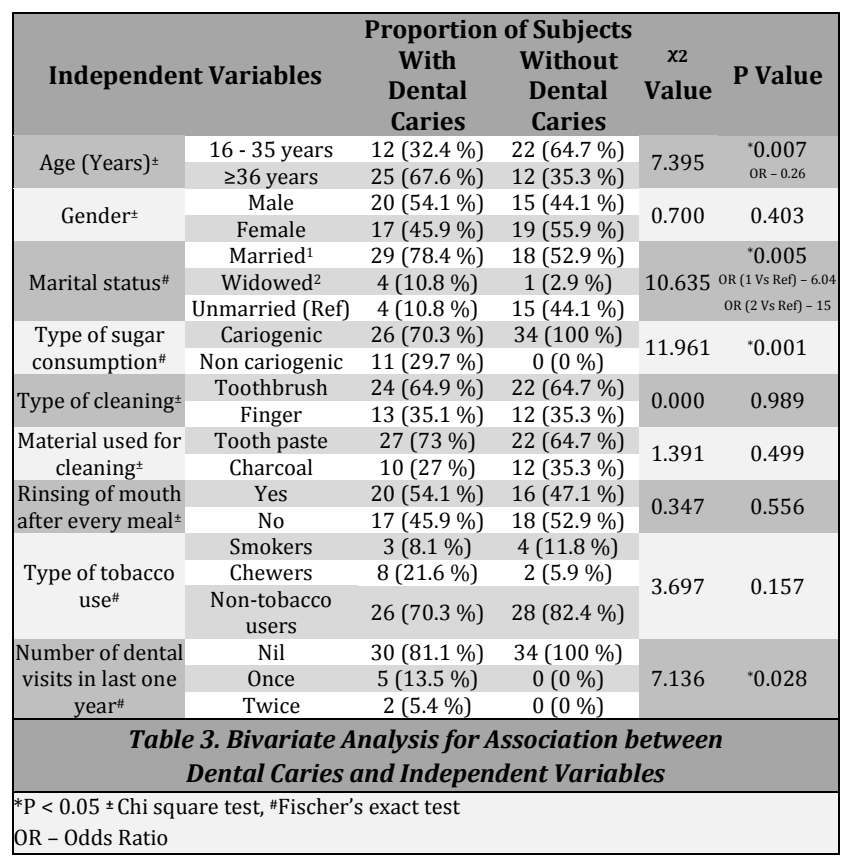

Prevalence of periodontal disease was found to be $57.7 \%$. Chi square / Fischer's exact test analyses were computed for each independent variable to assess their association between the subjects without dental caries and with dental caries (Table 3). Age (OR $=0.26$ ), marital status (OR married Vs unmarried $=6.04$ and OR widowed Vs unmarried $=15$ ), type of sugar consumption and the number of dental visits in the last one year $(\mathrm{P}<0.05)$ were significantly associated with dental caries.

\begin{tabular}{|c|c|c|c|c|c|}
\hline \multirow{2}{*}{\multicolumn{2}{|c|}{ Independent Variables }} & \multicolumn{2}{|c|}{ Proportion of Subjects } & \multirow{4}{*}{$\begin{array}{c}\text { x2 } \\
\text { Value } \\
17.978\end{array}$} & \multirow{4}{*}{$\begin{array}{c}\text { P Value } \\
\begin{array}{c}0.000 \\
\text { OR }-0.05\end{array}\end{array}$} \\
\hline & & With & Without & & \\
\hline \multirow{2}{*}{$\begin{array}{c}\text { Age } \\
\text { (Years)\# }\end{array}$} & $16-35$ years & $17(32.7 \%)$ & $17(89.5 \%)$ & & \\
\hline & $\geq 36$ years & $35(67.3 \%)$ & $2(10.5 \%)$ & & \\
\hline \multirow{2}{*}{ Gender $^{ \pm}$} & Male & $25(48.1 \%)$ & $10(52.6 \%)$ & \multirow{2}{*}{0.115} & \multirow{2}{*}{0.734} \\
\hline & Female & $27(51.9 \%)$ & $9(47.4 \%)$ & & \\
\hline \multirow{3}{*}{$\begin{array}{l}\text { Marital } \\
\text { status }{ }^{\#}\end{array}$} & Married $^{1}$ & $40(76.9 \%)$ & $7(36.8 \%)$ & \multirow{3}{*}{12.891} & \multirow{3}{*}{$\begin{array}{c}0.002 \\
\text { OR (1 Vs Ref) }-7.85 \\
\text { OR (2 Vs Ref) }-5.5\end{array}$} \\
\hline & Widowed $^{2}$ & $4(7.7 \%)$ & $1(5.3 \%)$ & & \\
\hline & Unmarried (Ref) & $8(15.4 \%)$ & $11(57.9 \%)$ & & \\
\hline \multirow{6}{*}{ Education" } & Primary $^{1}$ & $1(1.9 \%)$ & $0(0 \%)$ & \multirow{6}{*}{16.587} & \multirow{6}{*}{$\begin{array}{c}* 0.005 \\
\text { OR (2 Vs Ref) }-0.06 \\
\text { OR (3 vs Ref) }-0.10 \\
\text { OR ( } 4 \text { vs Ref) }-0.06 \\
\text { OR (5 vs Ref) }-0.03\end{array}$} \\
\hline & Middle school ${ }^{2}$ & $3(5.8 \%)$ & $3(15.8 \%)$ & & \\
\hline & High school $^{3}$ & $13(25 \%)$ & $8(42.1 \%)$ & & \\
\hline & Diploma $^{4}$ & $2(3.8 \%)$ & $2(10.5 \%)$ & & \\
\hline & Graduation $^{5}$ & $2(3.8 \%)$ & $4(21.1 \%)$ & & \\
\hline & Illiterate(Ref) & $31(59.6 \%)$ & $2(10.5 \%)$ & & \\
\hline \multirow{6}{*}{$\begin{array}{c}\text { Paternal } \\
\text { education" }\end{array}$} & Primary $^{1}$ & $2(3.8 \%)$ & $0(0 \%)$ & \multirow{6}{*}{15.216} & \multirow{6}{*}{$\begin{array}{l}\quad * 0.009 \\
\text { OR (2 Vs Ref) }-0.09\end{array}$} \\
\hline & Middle school ${ }^{2}$ & $1(1.9 \%)$ & $3(15.8 \%)$ & & \\
\hline & High school ${ }^{3}$ & $0(0 \%)$ & $3(15.8 \%)$ & & \\
\hline & Diploma $^{4}$ & $1(1.9 \%)$ & $0(0 \%)$ & & \\
\hline & Graduation $^{5}$ & $1(1.9 \%)$ & $0(0 \%)$ & & \\
\hline & Illiterate(Ref) & 47 (90.4\%) & $13(68.4 \%)$ & & \\
\hline \multirow{4}{*}{$\begin{array}{l}\text { Income } \\
\text { per } \\
\text { month }\end{array}$} & $<5000 \mathrm{Rs}$ & $22(42.3 \%)$ & $9(47.4 \%)$ & \multirow{3}{*}{0.200} & \multirow{3}{*}{0.905} \\
\hline & 5000 - 9999 Rs & $25(48.1 \%)$ & $8(42.1 \%)$ & & \\
\hline & $10,000-24,999 \mathrm{Rs}$ & $5(9.6 \%)$ & $2(10.5 \%)$ & & \\
\hline & \multicolumn{5}{|c|}{$\begin{array}{l}\text { Table 4. Bivariate Analysis for Association between } \\
\text { Gingivitis with Independent Variables }\end{array}$} \\
\hline \multicolumn{6}{|c|}{$\begin{array}{l}{ }^{*} \mathrm{P}<0.05 \pm \text { Chi square test, "Fischer's exact test } \\
\mathrm{OR}-\text { Odds Ratio }\end{array}$} \\
\hline
\end{tabular}

Variables such as gender, education, employment status, maternal education, paternal education, income per month, general health status, body mass index (BMI) scores, diet, staple food, fruit consumption per week, vegetable consumption per week, type of cleaning, method and frequency of cleaning, material used for cleaning, rinsing of mouth after every meal and type of tobacco use did not show a significant association. The chi - square / Fisher's exact test results showed association between gingivitis, periodontitis and independent variables such as age, marital status, education and paternal education $(\mathrm{P}<0.05)$ (Table 4 and 5).

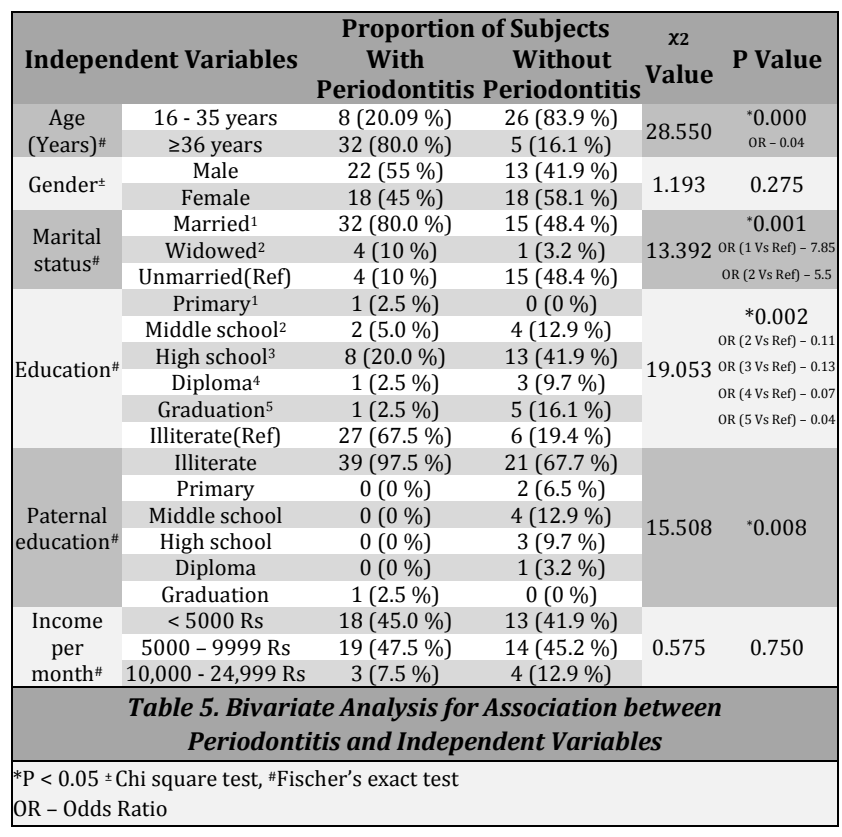

\section{DISCUSSION}

The present study was conducted with an objective to develop ROHD tool and identify the determinants of dental caries, gingivitis and periodontitis among the rural population of $\mathrm{T}$ Hosur village, Chikkaballapura district, Karnataka. There is lack of information pertaining to the determinants of oral health in this disadvantaged population. To our knowledge, there has been no validated tool published that measure comprehensively the determinants of oral health in rural population.

The majority of the adults in the study population were illiterate and unemployed. This can reflect the difference in the dental disease status that exists among individuals in the same situation. Although significant association was observed in the distribution of subjects with gingivitis and periodontitis according to the paternal education, there was no significant association with mother's education. These findings are in agreement with the study conducted by Gupta $\mathrm{R}$ et al. which had reported that the parental education has an impact on oral health and their relationship is reciprocal. ${ }^{12}$ On the other hand, paternal education did not show any significant association with the caries prevalence.

Majority of the study subjects consumed cariogenic sugar and a significant association was determined with the occurrence of dental caries. Numerous studies indicate a causal relationship between the sugar consumption and dental caries.17,18 It was reported that higher number of subjects with dental caries had not visited the dentist in last one year. These findings support the assumption that, in developing countries people tend to visit dentist only when emergency care is needed. ${ }^{19}$ The possible reason could be the 
lack of awareness about their oral health and poor accessibility to oral health care services.

In the present study, toothbrush was most commonly used to clean teeth and majority of the study participants reported of brushing once daily and rinse their mouth after every meal. Similar results were obtained from the studies conducted by National oral health survey and fluoride mapping, Karnataka. ${ }^{20}$ The improved oral hygiene practices in this rural population reflected their positive attitudes towards oral health. The present study showed a higher proportion of tobacco non-users and association of tobacco consumption was not found significant with the occurrence of periodontal disease. These findings differs from studies done by Malagi $\mathrm{S}$ et al. and Sekhon TS et al. which revealed a significant relationship between periodontal health status with chewing and smoking of tobacco. ${ }^{21,22}$

The prevalence of dental caries, gingivitis and periodontitis in our study population was found to be $50.7 \%$, $73.2 \%$ and $57.7 \%$ respectively. It has been documented that the prevalence of dental caries is very high among rural population in India with dental caries of $39.2 \%$, and $61.9 \%$ in $35-44$, and $65-74$ year old respectively. ${ }^{23}$ According to the National oral health survey and fluoride mapping, the prevalence of dental caries among the rural population was shown to be $60.4 \%$ and $79.4 \%$ in $35-44$ and $65-74$ year old respectively. ${ }^{19}$ Consistent with the findings of previous studies, the prevalence of dental caries were higher in the age group $\geq 36$ when compared to 16 - 35 years old. This might be due to increase in life expectancy and retaining their natural teeth for longer periods of time.

The present study did not observe any significant gender difference with respect to dental caries, gingivitis and periodontitis. Our results are similar to a study by Shah et al. which showed no significant gender difference in caries prevalence and in contrast to the findings of Rajaratnam et al. and Rao MV et al. where the caries status was found significant with female predominance. ${ }^{24-26}$ A study by Kumar et al. has reported that females had healthier periodontium than males. ${ }^{27}$ In our study, marital status was identified as a significant variable and dental diseases were seen significantly higher among the married subjects than the unmarried. Similarly, Singla et al. reported a significant association between marital status and periodontitis among the adult population attending dental outreach centers of Udupi District. 28

The results of the current study suggest that age, marital status, type of sugar consumption, number of dental visits in the last one year and paternal education are associated with dental caries, gingivitis and periodontitis.

\section{CONCLUSIONS}

The Rural Oral Health Determinants tool has acceptable validity and reliability and can be used as an effective tool to identify comprehensively the determinants of oral health among adults in rural and remote communities. Amongst the various determinants of oral health age, marital status, type of sugar consumption, number of dental visits in the last one year were found to be significantly associated with dental caries. Gingivitis and periodontitis were strongly associated with age, marital status, education and paternal education. Findings of this study suggest tailor made oral health care programs for specific target groups. Addressing these determinants of oral health improves the oral health status and provides opportunities in overcoming the existing disparities in health and disease among the rural population. We recommend further observational studies to be conducted to check the reliability and also to determine the causal relationship of these variables on larger rural adult population.

\section{Limitations of Our Study}

This study was subjected to several limitations. First, the distribution of subjects in each subgroup was relatively few, hence the ability of these determinants in predicting dental caries, gingivitis and periodontitis could not be analysed. Another possible limitation would be the response and social desirability bias as the data for the study relied on the response received from the subjects through ROHD tool. Findings of this study might need some caution in interpretation due to the homogeneity of study population in relation to social, economic and environmental factors.

Data sharing statement provided by the authors is available with the full text of this article at jemds.com.

Financial or other competing interests: None.

Disclosure forms provided by the authors are available with the full text of this article at jemds.com.

\section{REFERENCES}

[1] Georgieva L, Burazeri G. Health determinants in the scope of new public health-a handbook for teachers, researchers and health professionals. Hans Jacobs Publishing Company 2005.

[2] Park K. Park's Textbook of Preventive and Social Medicine. 23 ${ }^{\text {rd }}$ edn. Jabalpur: Banarsidas Bhanot 2015.

[3] Mathur MR, Tsakos G, Millett C, et al. Socioeconomic inequalities in dental caries and their determinants in adolescents in New Delhi, India. BMJ Open 2014;4(12):e006391.

[4] Petersen PE, Bourgeois D, Ogawa $\mathrm{H}$, et al. The gobal burden of oral diseases and risks to oral health. Bull World Health Organ 2005;83(9):661-9.

[5] Census Report 2011. http://www.censusindia.gov.in. [Last accessed on 2017 Jan 05].

[6] Maru AM, Narendran S. Epidemiology of dental caries among adults in a rural area in India. J Contemp Dent Pract 2012;13(3):382-8.

[7] Athuluru D, Reddy VC, Sudhir KM, et al. An epidemiological data of oral health status and treatment needs of rural population of Nellore district, Andhra Pradesh, India. J Indian Assoc Public Health Dent 2016;14(3):281-6.

[8] Agarwal V, Khatri M, Singh G, et al. Prevalence of periodontal diseases in India. J Oral Health Community Dent 2010;4:7-16.

[9] Dubey RK, Gupta DK, Shetty P. Current status of edentulousness in India: systematic review. Chhattisgarh J Health Sci 2013;1:72-6. 
[10] Batra M, Tangade P, Gupta D. Assessment of periodontal health among the rural population of Moradabad, India. J Indian Assoc Public Health Dent 2014;12(1):28-32.

[11] Miglani S. Burden of dental caries in India: current scenario and future strategies. Int J Clin Pediatr Dent 2020;13(2):155-9.

[12] Gupta R, Gaur KL, Sharma AK, et al. Comparison of associating factors of dental caries in urban and rural children in Jaipur, (Raj) India. J Dent Med Sci 2013;9(3):55-60.

[13] Mehta VV, Rajesh G, Rao A, et al. Social determinants of health and oral health: an Indian perspective. Indian J Occup Environ Med 2015;19(2):71-5.

[14] Bonfim MDLC, Mattos FF, E Ferreira MEF, et al. Social determinants of health and periodontal disease in Brazilian adults: a cross-sectional study. BMC Oral Health 2013;13:22.

[15] Lawshe $\mathrm{CH}$. A quantitative approach to content validity. Personnal Psychology 1975;(1):563-75.

[16] World Health Organization. Oral Health Surveys-Basic Methods. $5^{\text {th }}$ edn. WHO Publications 2013.

[17] Moynihan PJ. The role of diet and nutrition in the etiology and prevention of oral diseases. Bull World Health Organ 2005;83(9):694-9.

[18] Verma P, Verma KG, Rishi S, et al. Correlation between body mass index, dental caries and frequency of sugar consumption in adult population of Rajasthan State, India. Journal of Indian Academy of Oral Medicine and Radiology 2013;25(2):85-8.

[19] Sakri SB, Kishor KS, Nayak SK. Association of dental caries with utilization of dental care among rural children. Biohealth Science Bulletin 2010;2(2):69-72.
[20] DCI. Oral health status in national oral health survey and fluoride mapping. 2002-2003. New Delhi, India: Dental Council of India 2004.

[21] Malagi S, Hegde S, Kashyup R, et al. Effects of smokeless tobacco on gingival and periodontal status in adults: a case control study. Univ Res J Dent 2013;3(2):47-53.

[22] Sekhon TS, Grewal S, Gambhir RS. Periodontal health status and treatment needs of the rural population of India: a cross-sectional study. J Nat Sc Biol Med 2015;6(1):111-5.

[23] Shah N. National Commission on Macroeconomics and Health. Oral and dental diseases: causes, prevention and treatment strategies. New Delhi, India: Burden of Disease in India 2005:275-98.

[24] Shah N. Gender issues and oral health in elderly Indians. Int Dent J 2003;53(6):475-84.

[25] Rajaratnam J, Devi S, Asirvatham M, et al. Prevalence and factors influencing dental problems in a rural population of Southern India. Trop Doct 1995;25(3):99-100.

[26] Rao MV, Nathani A, Soma LS, et al. Prevalence of dental caries among rural population of Mustabad, Krishna District. J Int Oral Health 2016;8(4):481-3.

[27] Kumar A, Virdi M, Veeresha K, et al. Oral health status and treatment needs of rural population of Ambala, Haryana, India. Internet J Epidemiol 2010;8(2):70-1.

[28] Singla N, Acharya S, Prabhakar RV, et al. The impact of lifestyles on the periodontal health of adults in Udupi district: a cross sectional study. J Indian Soc Periodontol 2016;20(3):330-5. 